\title{
Use of Infra-Red Thermography for Automotive C mate Control Analysis
}

Steven D. Burch

Vahab Hassani

Terry R. Penney

Prepared for the Vehicle Thermal Management Systems Conference, Columbus, Ohio, March 29-April 1, 1994

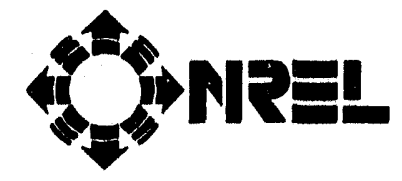

National Renewable Energy Laboratory 1617 Cole Boulevard Golden, Colorado 80401-3393

A national laboratory of the U.S. Department of Energy Operated by the Midwest Research Institute for the U.S. Department of Energy under Contract No. DE-AC02-83CH10093

March 1994 


\title{
Use of Infra-Red Thermography for Automotive Cllmate Control Analysis
}

\author{
Steven D. Burch, Vahab Hassani, Terry R. Penney \\ National Renewable Energy Laboratory
}

\begin{abstract}
In this paper, several automotive climate control applications for IR thermography are described. Some of these applications can be performed using conventional IR techniques. Others, such as visualizing the air temperature distribution within the cabin, at duct exits, and at heater and evaporator faces, require new experimental methods. In order to capture the temperature distribution within an airstream, a $0.25-\mathrm{mm}$ thick $(0.01$ inch) fiberglass screen is used. This screen can be positioned perpendicular or parallel to the flow to obtain three-dimensional spatial measurements. In many cases, the air flow pattern can be inferred from the resulting temperature distribution, allowing improved air distribution designs. In all cases, significant improvement in the speed, ease, and quantity of temperature distribution information can be realized with thermography as compared to conventional thermocouple array techniques. Comparisons are presented between IR thermography images and both thermocouple measurements and computational fluid dynamics (CFD) predictions.
\end{abstract}

\section{INTRODUCTION}

In the first half of this century, thermocouples and thermistors greatly simplified temperature measurement and enabled a vast array of thermal investigations not practical with glass bulb thermometers. In a similar manner, infra-red (IR) thermography is radically changing the way we measure and visualize temperature today. Although introduced commercially more than 20 years ago, recent improvements in technology have resulted in increased convenience and decreased cost.

IR thermography consists of an image radiometer with a sensor that is cooled to about $-200^{\circ} \mathrm{C}$. This cooling is typically done with liquid nitrogen, although some recent models make use of electrically powered Peltiereffect coolers. This cooling is necessary to achieve the greatest possible thermal resolution. In most systems, the sensor consists of a single infra-red detector (such as mercury/cadmium/telluride). Electromechanical servos (galvanometers) oscillate mirrors to perform horizontal and vertical scanning of the image onto the detector. The detector responds to the sum of the emitted, reflected, and transmitted energies (radiosity) coming from the target.

To obtain the target temperature, the emitted energy must be separated from the total radiosity. The emitted energy must be compensated (scaled up) by the target emittance to obtain an equivalent blackbody emittance. Finally, this blackbody emittance is converted to a temperature by reference to Planck blackbody distribution information. In this way, an IR imaging system can capture and process $10^{6}$ temperature measurements per second. These signals are digitized by a microprocessor and converted to grey-scale or color video images. A high-resolution video recorder can be used to store transient images for later post-processing. Typical personal computer or workstation post-processing capabilities include identification of isotherms, minimum and maximum temperatures, and temperatures along a particular line, curve, or boundary.

As a real-time interactive diagnostic tool, IR thermography provides non-contact, non-intrusive temperature measurement over an entire two-dimensional region, at as many as 40,000 resolution elements (pixels). Through proper image analysis and data reduction, thermography images can provide quantitative solid surface temperature assessments comparable in accuracy to thermocouple arrays $\left( \pm 0.4^{\circ} \mathrm{C}\right)$ [inframetrics, 1988]. This extremely high spacial resolution and ease of use provide ample justification for the relatively large initial cost of IR thermography systems. The purpose of this paper is to describe various automotive applications of IR thermography and some techniques for visualizing air temperatures. Detailed test results are not presented. Although this paper was restricted to black and white images, color versions are available from the authors upon request. 
In many areas of automotive design and optimization, IR thermography can provide significantly more information with less effort than thermocouple-based methods. Several examples have been previously reported, including a studies by Eloy [1989] on early detection methods for irregular tire wear and by Han, Song, and Dal [1992] on measuring the surface temperature distribution of clutch discs. Studies at the National Renewable Energy Laboratory (NREL) have included identification of high under-hood temperature regions and transient behavior of various catalytic converter heat shields (see Figures 1 and 2).

One of the primary areas of automotive thermal analysis effort, the passenger compartment heating, ventilating, and air conditioning (HVAC) system, has not received much attention in open literature. One notable exception is a paper by Carignano and Pipplone [1990], in which IR thermography is used to measure windshield defroster patterns during initial defroster outlet design. Significant time and cost savings were achieved by correlating windshield temperature patterns obtained at room temperature to ice melting patterns, which required 24-hour preparation in a refrigerated test chamber (see Figure 3).

Other potential HVAC applications for IR thermography include evaluation of heat exchanger (evaporator, condenser, and heater core) fin temperatures, locating primary sources of heat loss from the cabin during winter, and evaluating the ability of different window glazings to reduce summer cabin solar loading. These applications are fairly straightforward and have been used in the commercial and residential building industry for several years to identify heat loss, equipment failure, etc. Accurate temperature profiles can be obtained from knowledge of surface emissivities, or by correlating IR thermography readings to point measurements using surface-mounted thermocouples.

\section{IR MEASUREMENT OF AR TEMPERATURE}

For all of the advantages that IR thermography offers the thermal engineer, one significant restriction of the technique is that it is limited to measuring surface temperatures. It cannot be used to determine temperatures within a solid or fluid. For many aspects of HVAC design, the air temperature distribution is desired. Although air temperature cannot directly be measured with thermography, solids can be placed within the air stream in order to provide radiating medium. In order to minimize the effect of these solids on the flow patterns, and to provide the truest representation of spatially and temporally varying air temperatures, high-porosity screens have been used. Anderson [1990] originally developed the use of screens mounted perpendicular to the flow of air for buildings HVAC analysis. Researchers at NREL [Anderson, et al., 1991] have recently modified these

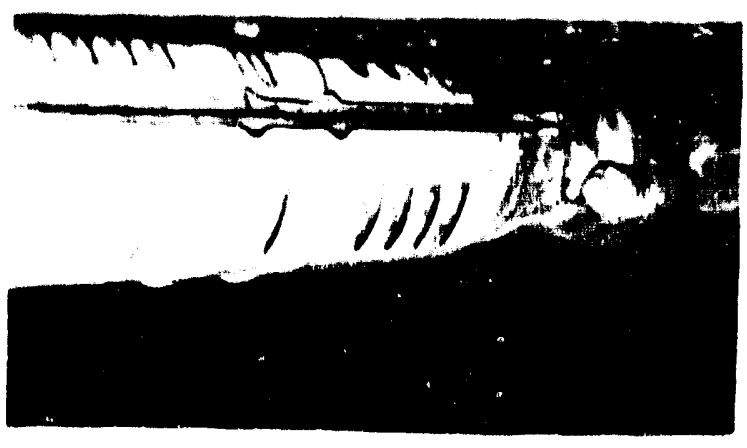

Figure 1 - Photograph of Catalytic Converter

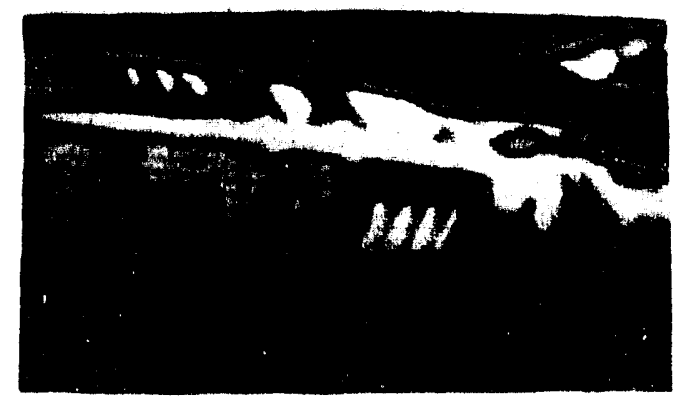

Figure 2 - IR Image of Catalytic Converter

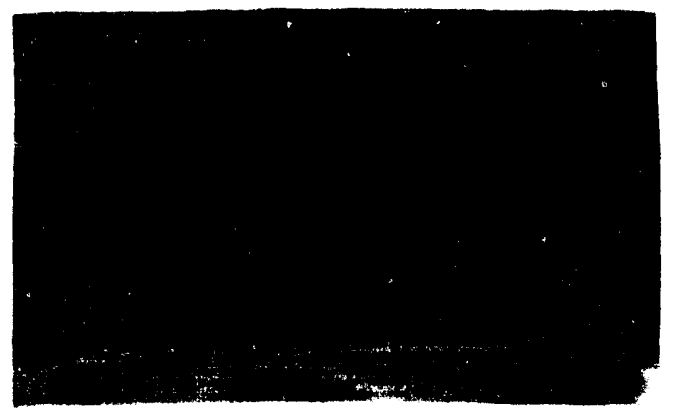

Figure 3 - IR Image of Windshield (Defroster Pattern) 
techniques to use IR thermography with screens mounted parallel to the flow to study the development of jets from - cold air diffusers in commercial buildings. Point comparisons of air temperatures using calibrated shielded thermocouples yielded IR thermography accuracy estimates of $\pm 1.3 \mathrm{C}$ (Figure 4).

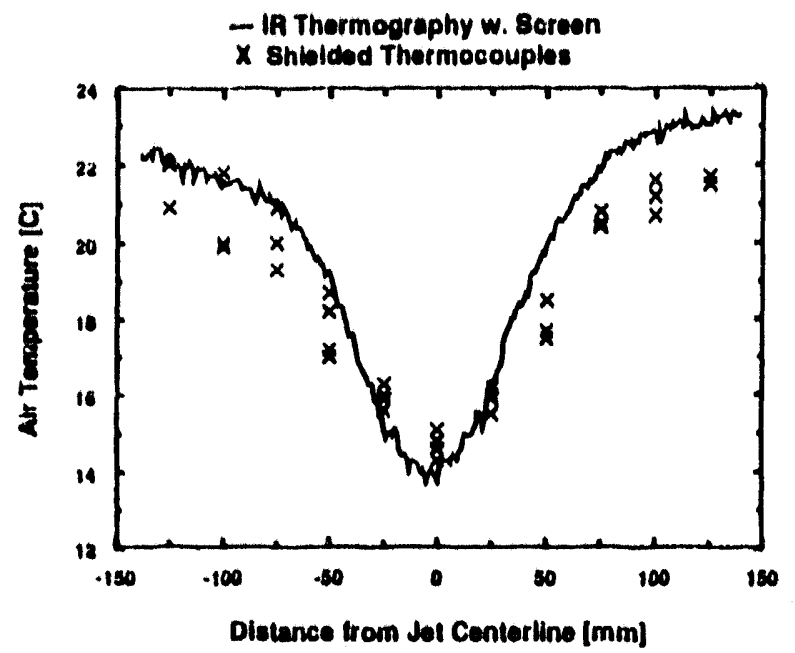

Figure 4 - Air Temperature Measurement: IR Thermography vs. Thermocouples

This two-dimensional temperature visualization is very well suited to comparison and qualification of computational fluid dynamics (CFD) codes. Use of CFD for practical automotive product design has become increasingly common as computers become more powertul and affordable and fluid dynamics theory and modeling areas such as turbulence are improved. CFD codes provide a wealth of detailed flow and temperature information, however, it is important to quality CFD models with experimental data. Obtaining and visualizing this qualification data is often a large task in itself. Use of conventional point measurement systems can involve substantial cost and delay to the overall analysis effort. IR thermography quickly provides the type of twodimensional temperature visualization that is common with CFD analysis software. Figures 5 and 6 show a comparison of an IR image and a temperature distribution of a cold air jet calculated using EXACT, a CFD code developed at the National Institute of Standards and Technology. This code was used extensively and applied to room air motions by A. Kirkpatrick [1992].

This low-mass screen technique is currently being extended to HVAC studies in automobiles. Figure 7 shows the behavior of a jet of cold air from the center panel AVC outlet of an automobile. In Figure 8, a person has been added to the driver's seat. The jet can be seen to be deflected upwards, creating a region of hot, uncooled air at the floor. For this study, a $0.25 \mathrm{~mm}$ thick fiberglass screen with a porosity of $70 \%$ was used. The thermal response of the screen was approximately 0.3 seconds.

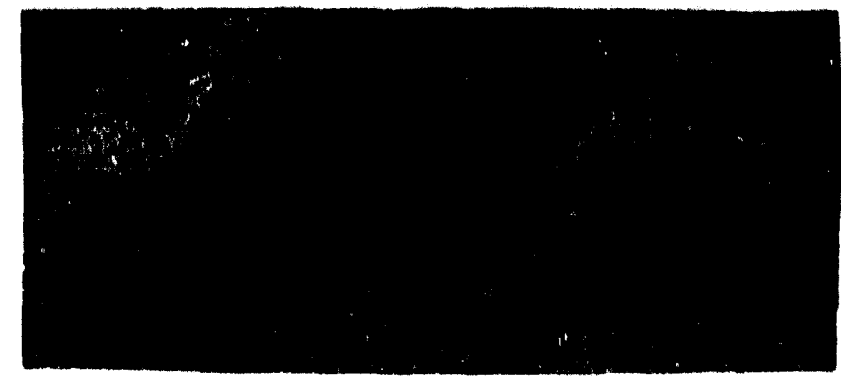

Figure 5 - IR Image of Ceiling Jet Air Temperature

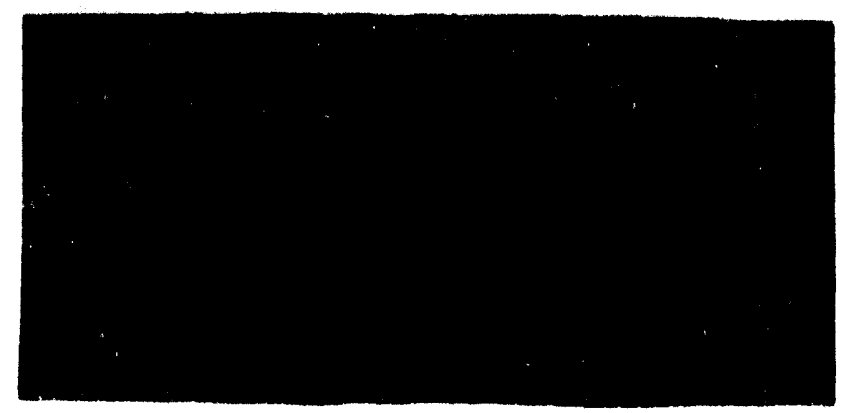

Figure 6 - CFD Output of Ceiling Jet Air Temperature

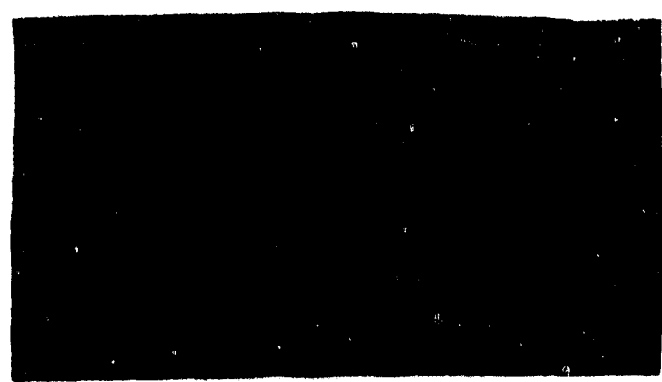

Figure 7 - IR Image of Cabin Air Temperatures

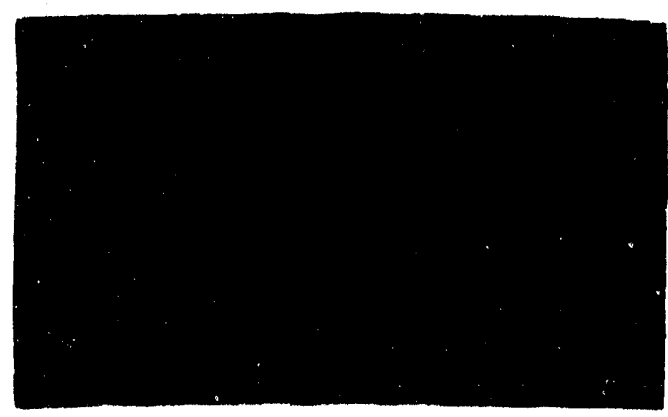

Figure 8 - IR Image of Cabin with Passenger 
The experimental setup used in this study is shown in Figure 9. Note that the passenger-side window must be rolled down prior to recording the image. Although very transparent in the visible spectrum, standard silica glass is nearly opaque to IR. If desired, a thin $(0.15 \mathrm{~mm})$ layer of polyethylene plastic can be used across the passenger-side window. Because the transmissivity of this plastic is 0.87 in the IR spectrum, the temperature of the screen and other interior surfaces will be detected through the polyethylene plastic with good accuracy.

Depending on the porosity of the screen used, there may be substantial error introduced to the air temperature measurements across the screen due to thermal radiation transmitted through the screen from background surfaces. For qualitative studies such as the AC air jet development shown in Figures 6 and 7, this error may not be significant. When desired, the effect of background radiation can be reduced in at least two ways. In some cases, a uniform temperature surface with very low emissivity, such as a white or aluminum foil-backed foam insulation board, can be inserted behind the screen. In other cases, this may not be practical or may introduce changes in the air flow distribution.

An alternative available with many IR thermography systems is to store an image of the background surface temperatures and then subtract this image from the actual case. For example, if in Figure 7, an IR image taken with the HVAC blower off, and this image is subtracted from an image with the blower on, the resulting "calculated" image will provide a more isolated representation of the screen temperature, and hence the air temperature distribution.

In addition to cabin air temperature, IR thermography can be used to visualize the air temperature distribution within an automotive HVAC module. This can be particularly useful for optimization of mixing of the airstreams from the evaporator and the heater core. Holes in the module can be cut and replaced by plastic fllm to provide viewing access.

\section{CONCLUSIONS/OPPORTUNITIES}

IR thermography provides a powerful tool for rapid two-dimensional non-intrusive temperature assessment of a wide variety of automotive applications. Its portability, ease of use, and convenient video tape nr computer disk data storage capabilities provide unique practical advantages over other temperature measuring devices. Although inherently a surface ternperature measuring technique, IR imaging can be used with low-mass, highporosity screens to capture air temperature distributions. In addition to the cabin and HVAC module air temperature examples discussed in this paper, IR thermography has many other potential automotive applications such as front-end (underhood) air temperature distribution, transient exhaust gas temperature, and investigation of alterative cabin cooling systems such as roof-mounted photovoltaic-powered ventilators.

\section{REFERENCES}

Anderson, R., 1990, National Renewable Energy Laboratory, personal communications, August 1990.

Anderson, R., Hassani, V., and Kirkpartick, A., 1991, "Visualizing the air flow from cold air ceiling jets," ASHRAE Journal, May 1991, pp. 30-35.

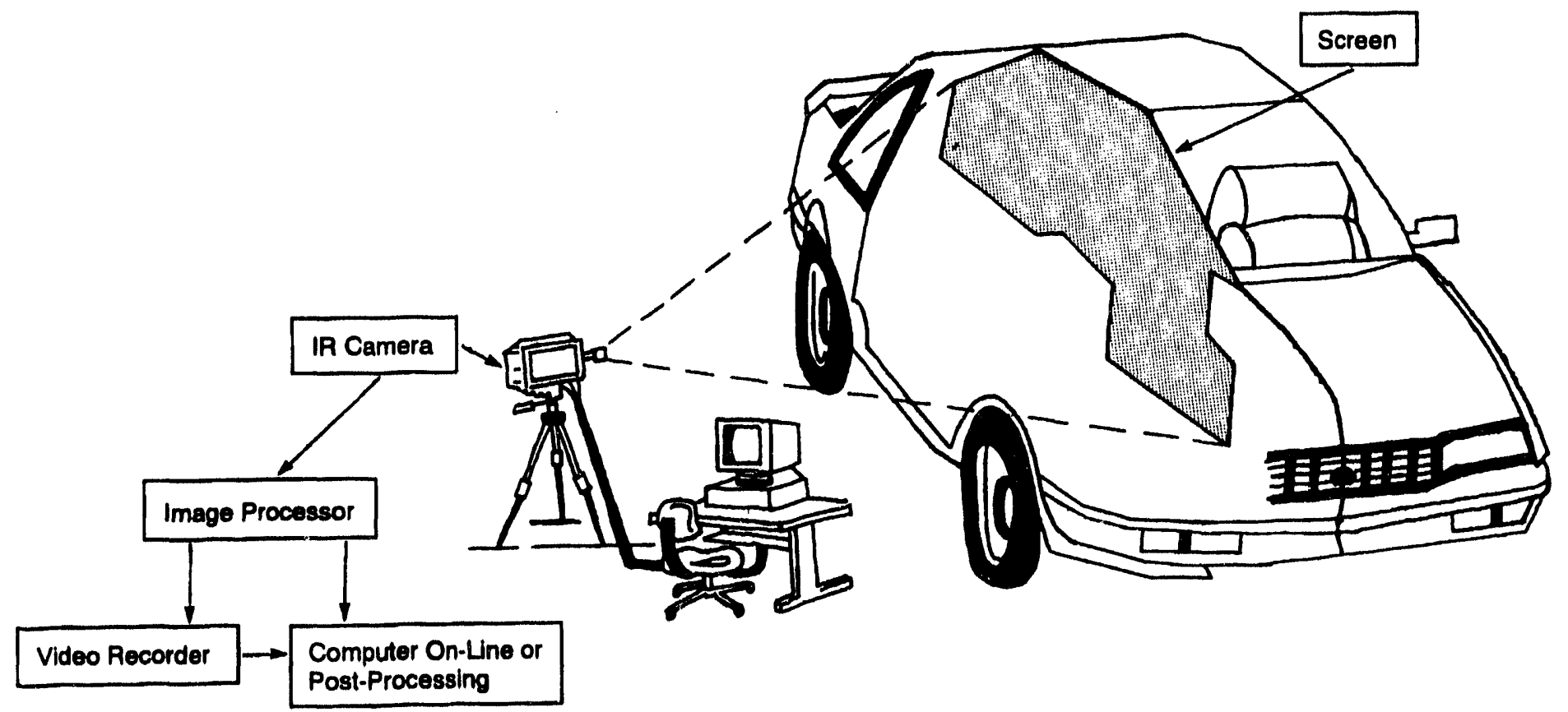

Figure 9 - Setup for Cabin IR Imaging Tests 
- Carignano, M., Pipplone, E., 1990, "Optimization of windscreen defrosting for industrial vehicles via computer assisted thermographic analysis," SAE Technical Paper \# 905237.

Eloy, X., 1989, "Analysis of the causes of irregular wear of tyres, investigation methods," SAE Technical Paper \# 890088.

Han, Z., Song, W., Dal, B., 1992, "Measuring surface temperature distribution on clutch discs," SAE Technical Paper \# 922094.

Inframetrics, 1988, Inframetrics 600 Operator's Manual, Document \#05250-200, Rev. C., Inframetrics, Inc., May 1988.

Kirkpatrick, A., 1992, University of Colorado at Boulder, personal communications, February 1992. 

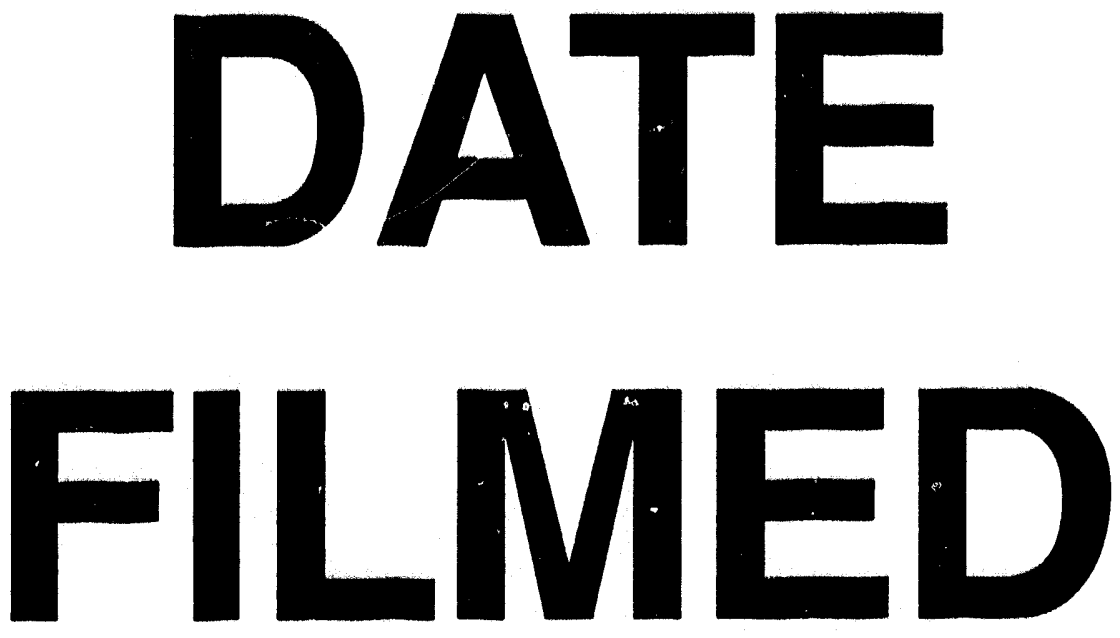

$6 / / / 94$
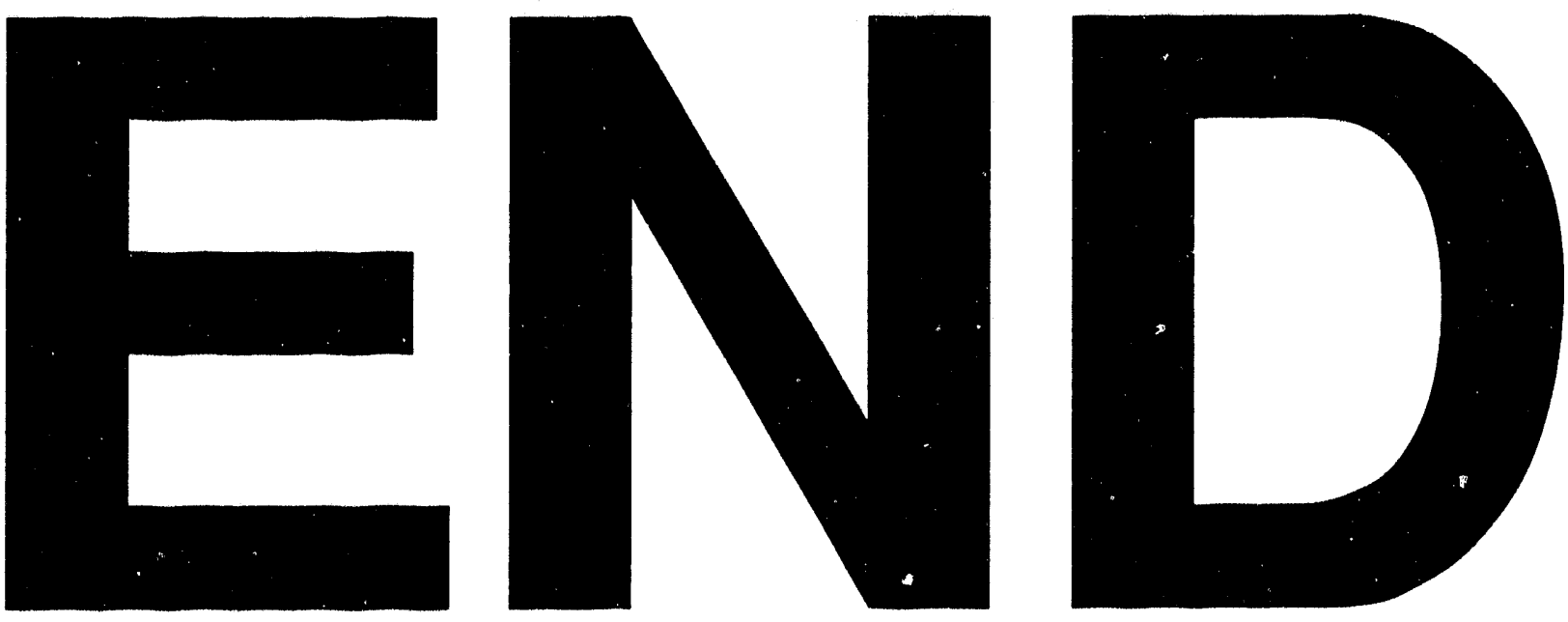
